\title{
Vertical equity in access to health insurance services: A qualitative analysis of perceptions and enrolment in the Jirapa Municipality, North-western Ghana
}

Maximillian Kolbe Domapielle ( $\nabla$ mdomapielle@uds.edu.gh )

University for Development Studies https://orcid.org/0000-0002-0807-0420

Constance Awinpoka Akurugu

University for Development Studies

Emmanuel Kanchebe Derbile

University for Development Studies

\section{Research}

Keywords: Health insurance, Vertical equity, Premium, Access to health care, Ghana

Posted Date: June 16th, 2020

DOI: https://doi.org/10.21203/rs.3.rs-35091/v1

License: (c) (1) This work is licensed under a Creative Commons Attribution 4.0 International License.

Read Full License 


\section{Abstract}

Abstract Background: Cost continues to be an important barrier to accessing health services in Low and Middle Income Countries (LMICs) partly due to the inability of health systems in those settings to adequately implement equity measures that aim to offer financial protection to disadvantaged population groups such as indigenous and rural residents. Drawing on a framework for assessing financial access to health services, this article provides evidence of vertical inequity in the distribution of the cost of national health insurance contribution among rural and urban residents in a municipality in northern Ghana. Methods: A qualitative approach was used to collect and analyse the data. Specifically, the concurrent use of in-depth interviews and observation provided the needed data to critically analyse the relationship between location, livelihoods and ability to pay for health insurance services. Results: The paper argues that flat rate contributions for populations in the informal sector of the economy and lack of flexibility and adaptability of timing premium collections to the needs of the poor contradict the vertical equity objectives of the National Health Insurance Scheme (NHIS). The current payment arrangement makes the cost of NHIS membership disproportionately higher for rural residents. Conclusion: As this might deter them from enrolling in the scheme as much as their urban counterparts, we advocate strict adherence and implementation of the scheme's vertical equity measures through the adoption of the Ghana National Household Register (GNHR) as a tool for ensuring that contributions are graduated according to income and collection is well-timed.

\section{Background}

While global support for Universal Health Care (UHC) is on the rise, scholars in this field have questioned whether health services across the globe have delivered on equity. The studies provide evidence that those who are poor in income have remained poor in health (Mooney, 2000b, Kusi et al., 2015a, Kotoh et al., 2018). Same is true for minority ethnic groups and indigenous peoples, and in some cases gaps in illhealth have increased (1). The National Health Insurance Scheme in Ghana (NHIS) has made significant progress in terms of enrolment of members, which has had a commensurate increase in the utilization of health care services (2-4), yet questions are raised about progress towards achieving its equity objectives. This article contributes in-depth stakeholder perspectives to the discourses around equitable and progressive health financing in LMICs. It analyses perceptions of vertical inequity in access to health insurance services and implications for eliminating disparities in health care access among urban and rural populations.

Promoting equity in health care access through pre-payment arrangements such as national health insurance schemes has increasingly gained political support in low and middle income countries. It has been argued that reliance on out-of pocket payments for health has led to close to half the world's population still lacking access to essential health services. Additionally, some 800 million people are trapped in catastrophic health spending, and close to 100 million people are impoverished each year because of out-of-pocket health expenses (5). To reverse these statistics, the World Bank Group and the World Health Organization (WHO) have been supporting countries to implement pro-poor health financing 
programmes to enable them increase access to essential health services, eliminate catastrophic health spending, and transition towards UHC by 2030. To this end, Universal Health Coverage has become a preferred health policy objective in implementing countries because in theory it guarantees equitable financial protection against the costs of illness and makes it possible for all residents to have access to needed health care (6-8). And while research shows that people living in countries that have achieved UHC live longer and healthier than those living without it (9), another important argument for the policy is that it is an investment in human capital and a foundational driver of inclusive and sustainable economic growth and development $(5,10,11)$. It is no surprise therefore, that, in 2015 , all United Nations (UN) member states committed to achieving universal health coverage through the health-related sustainable development goal (SDG 3) (Witthayapipopsakul et al., 2019).

Prior to the UN member states UHC reforms declaration, Ghana passed the National Health Insurance Act (NHIA) in August 2003, and commenced implementation in 2004 (12). The NHIA's health financing trajectory is characterised by a series of reforms, but, perhaps a significant starting point would be the free health care programme that followed Ghana's attainment of independence from British colonial rule. The new government, led by Dr Kwame Nkrumah adopted a welfare system and used taxes to finance public sector health services that included free health care for all (13-15). Health financing reform again became central to the government's policy initiatives in the 1980s and the 1990s when it subscribed to implement the IMF/World Bank Structural Adjustment and Economic Recovery reforms. As part of the reforms, public sector user fees for health care, also known as the 'cash-and-carry system', was introduced in 1985. While this policy measure resulted in improved supply of essential medicines and quality health care delivery in general, it created inequities in financial access to basic health care services $(13,16,17)$. Other studies observed that financial barriers, ushered in by the cash-and-carry system, forced poor households to regularly postpone medical treatment, resort to self-medication, or rely on cheap quack practitioners, which might have harmful consequences $(18,19)$. Although mutual and community health financing schemes were implemented across the country to soften the harsh consequences of the cash-and-carry system, the most comprehensive national health financing reform programme since Nkrumah's free health care project was the introduction of the NHIS. Although the Scheme has made progress both in terms of enrolment and uptake of health care services it has not delivered on vertical equity.

The ensuing sections of the paper commence with an exploration of the theoretical and operational meanings of equity and highlight a shift from the often ambiguous interpretation of equity in health in order to locate the study within to a more specific operational dimension called vertical equity. This is followed by the question of 'affordability of health services' as the conceptual framework for assessing vertical equity in the NHIS. The paper goes further to provide study context and methodology, results and discussion around perceptions of vertical inequity in the distribution of the cost of membership in the NHIS. It recommends the adoption of 'positive discrimination[1]' in order to achieve the scheme's objective of ensuring that every Ghanaian resident gets access to basic health care. In the context of a policy shift on health financing in Ghana, the findings of this study are useful for triggering policy reform and redesigning of relevant operational strategies to enable the scheme achieve its vertical equity 
objectives as well as contribute to the body of knowledge on equity in NHIS enrolment and progress towards attaining UHC and the SDGs.

\section{Equity in health care: A health insurance perspective}

Equity is primarily concerned with fairness and justice. However, the practical application of such concepts has often been met with interpretation and prioritisation difficulties (1, 20-22). In the discourses around health care access, equity is often interpreted as providing effective health care for all residents $(20,22,23)$. This definition however, is shrouded in ambiguity and therefore inadequate when the focus is on implementing a specific policy on equity in health $(20,21)$. For example, a variety of studies that explored perceptions of equity in the NHIS have often tended to focus generally on the socioeconomic or sociodemographic factors associated with enrolment and dropout $(3,24-26)$. Other studies have examined the subjects of equity and affordability in the NHIS and arrived at the conclusion that the flat rate payment of premiums by those in the informal sector favoured richer people, although the burden of illness was greater for lower-income groups (27-31). This study attempts to shift away from the often extensive interpretation of equity in the distribution of the burden and benefits of the NHIS to a specific operational dimension known as vertical equity. This makes it relatively easier to unpick the hidden inequity issues in the scheme and recommend reform measures that will promote its vertical equity objectives. Although previous studies have made the point that health services across the world have failed to deliver on vertical equity and that there is a need for positive discrimination to promote equity in health $(1,23,32)$ this subject has not specifically been addressed in the context of the NHIS in Ghana.

Vertical equity is about treating individuals or communities who are unequal differently in a way that is seen to be commensurate with their relative disadvantage. This differs from horizontal equity which focuses on ensuring that people in the same circumstances are treated the same $(21,23)$ Vertical equity has been the focus of some health systems because it serves as a form of positive discrimination to promote equity in health services delivery. Examples such as the use of resource allocation formulae in Canada, Australia and South Africa, and user fee exemptions in Cambodia represent vertical equity measures aimed at distributing resources to reflect the higher health needs of disadvantaged population groups including indigenous and rural residents $(1,20-22)$. The financial objective of vertical equity is usually about ensuring that payment for health care reflects users' ability to pay. This is particularly important because the uncertainty and unpredictability of ill health can make the consequences of paying out-of-pocket for health care catastrophic for poor households (33).

The concept of financial equity, has been considered in two phases. The first is the achievement of equity based on ability to pay, and the second is that, within groups of equal financial status there is actual payment on fair terms, meaning that attention is paid also to horizontal equity. The NHIS has a vertical equity objective anchored in Act 852, section 28 of the Legal Instrument that established the NHIA which states that informal sector contributions be graduated according to income (34). Thus, in theory, contributions are to be based on ability to pay. In consonance with this legal requirement, vulnerable groups such as indigents, beneficiaries of the Livelihood Empowerment against Poverty (LEAP), pregnant 
women, children under the age of 18 , adults above 70 years and SSNIT pensioners are exempted from paying the fixed contributions. The question is, do the flat rate contributions for those outside the formal sector, and the inflexible manner in which these contributions are collected reflect the vertical equity objective of the scheme? This is an important question because previous studies in LMICs have observed that exemption schemes targeting specific vulnerable groups (such as pregnant women, children under 5 years of age, and the elderly) are often relatively effective. However, exemption packages that require means testing to identify beneficiaries tend to be less effective due to the difficulty of appropriately assessing eligibility $(6,35)$. Two reasons are associated with this: the first is the absence of reliable income records for a large proportion of the population working in the informal sector of the economy in order to ascertain how much users can pay and eligibility for exemption. The second reason is the stringent, and sometimes inappropriate criteria used in assessing eligibility for exemption. For these reasons, premiums are charged at a flat rate; mostly unaffordable to the poor (35-38). Fortunately, a significant policy measure is currently being implemented by the Ghana National Household Registry (GNHR), a unit under Ministry of Gender, Children and Social Protection to establish a single national household register from which social protection programmes will select their beneficiaries. The GNHR is mandated to streamline and make more efficient the targeting system in the country by using the same Proxy Mean Test indicators (Common Targeting Mechanism) in the identification of potential beneficiaries for social protection interventions (39). This register is expected to bridge the gap in access to reliable income records for those in the informal sector. Some progress has already been started in this regard and all the households in the two poorest regions in the country: the Upper West and Upper East Regions have already been registered. The information generated and documented in the register will enable the scheme to accurately identify indigents and other vulnerable groups to benefit from exemptions, as well as to ensure that contributions by populations in the informal sector are graduated according to income and the timing of collection is favourable.

Another important, yet, often ignored equity consideration is the timing for collection of health insurance contributions. A few studies have discussed the importance of appropriately timing the collection of health insurance contributions from different socio economic groups and arrived at the conclusion that the timing of collection of contributions is likely to affect enrolment. For this reason, it is advisable for schemes to design suitable payment schedules that take into consideration the nature, timing and income sources of households (40-44). As a general rule of thumb, the best time to collect contributions is when users have cash, for example, during or immediately after farmers have harvested their food crops, or when they receive a loan or a government cash transfer (43). The NHIS has recognised the importance of timing the collection of contributions by instituting in its design a requirement that municipal and district schemes have different registration periods; major and minor seasons, with the major season set to coincide with agricultural cycles (44). The Jirapa Municipal Health Insurance Scheme operates an open registration system throughout the year, although 82.7 percent of its population is employed in seasonal agriculture. This raises concerns that a significant portion of its rural population might be excluded from the scheme. 
In designing a health care financing scheme of fair contributions it is important to take into consideration the different payment mechanisms that can be employed. A tax-financed health care system or a social insurance system is expected to achieve some degree of vertical equity. Those health care systems that rely heavily on large out-of-pocket payments for finance are more likely to require regulation (e.g. means testing) to protect low-income and high-user groups (21). Other examples include exemptions on user fees and progressive payment scales for social health insurance levels. Policies that target disadvantaged groups in this way represent the application of vertical equity. With reference to the South African health system, Mclntyre, Muirhead (45) observed that in spite of considerable debates around the most appropriate way to define the concept of equity, the vertical approach is arguably the most appropriate means of effectively and speedily achieving equity, given that it recognises that different groups within the society have different starting points and therefore require differential treatment.

\section{Conceptual framework for assessing vertical equity}

The framework for effective implementation of vertical equity revolves around the concept of "affordability of health services". Based on the review of literature, two interlinked dimensions of access are key for conceptualizing a framework for the study and these include costs and mode of paying NHIS contributions and users' ability to pay. This framework presents affordability as a two-dimensional concept and, one that disaggregates the broad concepts into two interlinked dimensions that makes it possible to firstly, evaluate the achievement of the scheme's vertical equity objectives and secondly, identify appropriate measures for improving the implementation of vertical equity in the NHIS. The relationships between these two dimensions of cost and mode of paying NHIS contributions and users' ability to pay are depicted in Figure 1 .

Affordability refers to the relationship of prices of health care services and users' ability to pay in the context of the household budget and the other demands on the budget $(46,47)$. Besides the direct costs of a range of items such as consultation fees, "under-the-counter" fees, diagnostic tests and medicine charges, and ward and theatre fees, there are also indirect costs that deter the poor from seeking treatment when they need it. These include the opportunity costs of time of both the patient and household members accompanying them, transportation costs and expenses on food and lodging (29-31, $46,48)$. These writers argue that the availability of public funding, especially subsidised health insurance, influences the extent to which users can afford to pay for these services.

Ability to pay refers to the individual's ability to secure funds from their household and the other demands placed on those potential sources of funds $(46,47,49)$. These include firstly, the eligibility of individuals to secure health insurance to cover the costs of health services at the time of service use. Secondly, the ability of the household to pay for the service at the point of use, including the amount, timing and frequency of income flows, and the individual's ability to draw on these sources of income; the amount of cash savings that can be spent on health; household assets and whether these assets can be easily converted to cash; households' social capital from which they can mobilize cash; the ability to secure formal credit arrangements. Thirdly, the ability of individuals to incur indirect costs such as sick leave 
benefits to protect income while incapacitated for employees (46). The notion of catastrophic spending on health care[2] is also important in the analysis of affordability of health services. Some people may be able to pay the full costs of health services at the expense of other basic household needs. This pattern of household spending is described as catastrophic health expenditure $(46,48,50)$. While much of the literature on affordability has focused almost exclusively on individuals' or households' socioeconomic status as the main determinant of enrolment in the NHIS, the influence of costs of contributions and the timing of payment leading to variations in enrolment and use of health care between urban and rural residents in Ghana has not been specifically researched. For example, do rural residents have equitable financial access to the health care and NHIS services? Is the mode of payment and timing of the collection of premiums friendly to seasonal income flow of rural residents in particular? These questions reverberate with the WHO's view that health services are equitable and affordable if households are not paying more than they are able to, or that payment for health is not made at the expense of other basic needs (48).

\section{Methods}

\section{The study context}

The Jirapa Municipality, established by LI 1902 was carved out of the then Jirapa-Lambussie District in 2007 as part of the expansion and deepening of Ghana's decentralization process (51). The District is located in the north western part of the Upper West Region[1] of Ghana. It is one of eleven municipalities/districts in the region and lies approximately between latitudes $10.25^{\circ}$ and $11.00^{\circ}$ North and longitudes $20.25^{\circ}$ and $20.40^{\circ}$ West with a territorial size of $1,188.6$ square kilometres representing 6.4 percent of the total regional landmass. Jirapa Municipality is bordered to the north by the LambussieKarni district, to the south by the Nadowli-Kaleo District, to the east by the Sissala West District and to the West by Lawra District. The capital, Jirapa, is $62 \mathrm{~km}$ away from Wa, the Regional capital (51)(51). The map below shows the boundaries and some of the major communities of the Municipality where data for this article were collected.

The municipality has a population of about 102,767 , and 85.6 percent of this number reside in rural areas (52). Agriculture is the main livelihood activity and an estimated 82.7 percent of households are engaged in subsistence agriculture (GSS, 2014). Three different surveys have found that income poverty in Ghana is disproportionately higher in rural areas, and is highest among subsistence farmers (53-55). The Municipality is located in the Upper West, the poorest region in Ghana. Poverty statistics in the Upper West Region are as high as $66 \%, 18 \%$ and $16 \%$, representing extremely poor, poor and no-poor respectively (39). Douri, Yaga, and Tuggo[2], where this study was carried out are three of the six underserved sub-municipalities in the Jirapa Municipality. Current NHIS membership covers 52 percent of the population of the Municipality, but active contributors constitute only 23.5 percent of this figure (56). A combination of these statistics and the high incidence of poverty in the Municipality suggest that a significant segment of the population outside the exempt categories would encounter difficulties in an attempt to raise enough funds to pay for NHIS membership. 


\section{Study design}

A qualitative approach was employed in the collection and analysis of data. In addition to reviewing relevant literature on equity and financial access to health services, the study collected data through indepth interviews, observation and relevant secondary sources between 2015 and 2020. A total of 33 indepth interviews were conducted with key informants, including NHIS officials, users of health services (enrolled, previously enrolled and never enrolled) health providers and health administrators using a multilevel sampling procedure.

Multi-stage sampling was employed to select the study municipality, sub-municipalities, communities in the sub-municipalities, and the research participants. The Jirapa Municipality was selected on the basis that, although largely rural, it has a sizeable urban population that satisfactorily enables the exploration of rural-urban differences in financial access to health services. The second stage involved the selection of sub-municipalities within the Municipality. The Jirapa urban sub-municipality and three rural submunicipalities including Douri, Tuggo and Yaga, were purposively selected from a total of seven to represent geographically and economically diverse areas. In each of the four sub-municipalities, three communities were purposively selected on the basis of population size, location and livelihood activities. Thus in each sub-municipality, the first community selected is the most populated, centrally positioned and one that provides diverse social and economic services to rural communities within the catchment area. The remaining two are predominantly farming villages that are at least 5 kilometres away from the central community.

Similar to the mode of selecting the municipality, sub-municipality and communities, key informant interviewees were purposively sampled for the study. They were 33 in all, including 24 users of health care services (comprising 12 males and 12 females), four providers of health care services, and three officials and two agents of the NHIS. Aside from gender balance, other key considerations for selection were locality and enrolment statuses of participants, their understanding of health insurance issues in the Municipality and willingness to participate in the study. From the 24 users who participated in the study 12 were selected from rural areas and 12 were urban residents. The even distribution of participants was to ensure a balanced coverage of perceptions of users from both rural and urban areas on the subject of vertical equity in the implementation of the NHIS. Each sub-municipality had six participants. From this number, two (a male and a female) were sampled from the central community of the sub-municipality and four (two females and two males) were selected from the other two communities. In addition to interviewing users, four heads of sub-municipal health centres, a public health nurse at the Jirapa Municipal health secretariat, a midwife and a medical doctor at the Jirapa Municipal Hospital and one official from the Upper West Regional Health Directorate were also interviewed in depth. This group of participants were sampled for the study because their respective roles in the health system made their contributions relevant in addressing the research questions. The last group of participants interviewed were four officials of the NHIS. This category of participants demonstrated a good understanding of the dimensions of access to health care in the Municipality, including the prospects and challenges of expanding health insurance coverage to underserved areas. 
Non-participant observation was also carried out to compliment data gathered via interviews. For example, in the absence of records on household income levels, we relied on proxy indicators such as the types of houses interviewees lived in, to get a sense of socioeconomic status, which gives an indication of their ability to pay for health services. Houses built with mud and roofed with thatch were an indication of the households' low level of income, which shows that members of such households may be facing challenges in paying out-of-pocket to access health services. However, houses built with cement bricks and roofed with zinc sheets or baked roofing tiles were a reflection that members may be relatively welloff (57), and thus able to pay out-of-pocket for health services with greater ease.

Following the collection of data the framework approach to thematic analysis was employed to analyse the dimensions of equity of access to health care services in the municipality. Thus, the analytical process started right from the stage of developing the data collection instruments where the questions were structured to focus on the vertical equity dimension of the framework. The process involved transcribing and getting familiar with the data. It also involved reading each interview transcript line by line, noting down repetitions, similarities and differences that were relevant to the research questions. For example, if 'users' mentioned lack of money as the reason they failed to enrol or renew the membership, we would write this down under 'Affordability - lack of money.' At the margins of each page we wrote down the main themes that had come from the page's conversation. From this preliminary analysis, we examined the themes a second time and then put them into the thematic networks. For the final phase, we used the soft copies of the transcripts to pull together the segments of data that represented each theme and developed qualitative analysis by analysing in detail what users, providers, officials of the NHIS said about these themes and what they signified in relation to the research question. In terms of secondary analysis of data, the article draws significantly on findings of the $5^{\text {th }}$ and $6^{\text {th }}$ rounds of the Ghana Living Standard Surveys (GLSS 5 and 6), the 2010 Ghana Population and Housing Census report, annual reports of the Ghana Health Service and the Ministry of Health, and annual reports of the NHIS.

\section{Ethical consideration}

Ethical issues involving research with human participants, including anonymity, confidentiality and consent were considered at the outset of the research. Following the selection of the Municipality, permission was obtained from the Regional and Municipal Health Secretariats to carry out the research. Additionally, permission was sought from the Regional Director of the National Health Insurance Scheme and the Municipal Manager of the Jirapa Municipal Health Insurance Scheme to interview staff of the NHIS for the study. Anonymity and confidentialitywere strictly adhered to during this research. Informed consent was sought from all participants prior to conducting each interview. The purpose of the study was explained to each of them. The participants were also assured of strict anonymity and confidentiality, and data collected have been managed as such. Participants were informed that their decision to participate in the study was completely voluntary and that their responses were anonymous. They were given the possibility to withdraw from the study at any time and to skip any question(s) they did not wish to answer. All information provided by participants was treated as strictly confidential. Interviews were conducted in English for interviewees who speak it, and in Dagaare (the local language) 
for non-English speakers. Interviews were audio recorded (with the consent of interviewees) and transcribed, and quotations have been anonymised.

\section{Results}

In this section we discuss the research findings on cost of health services and NHIS contributions. The results reveal contrasting perceptions of the costs of NHIS services among rural and urban populations in the Municipality. These relate to the costs of health insurance contributions, registration and renewal fees, and rigidities in timing of collection of contributions. These perceptions have tended to influence their enrolment decisions, as the ensuing findings demonstrate.

\section{Cost of Health Services and NHIS contributions}

In terms of the cost of NHIS contributions, the analysis produced mixed results. Users, providers, and NHIS agents attributed failure to enrol or dropping out of the scheme to expensive premiums. They argued that large household sizes, subsistence livelihood activities, and irregular flow of incomes are factors that make payment of premiums difficult. Like most rural residents interviewed for this research, a household head from Kol-Ora whose farm produce were barely enough to feed his household of eight people, had this to say when asked about his ability to pay the NHIS premiums for his household;

"I have only managed to raise money for my three younger children. My older children are not covered by the scheme because there is no money to pay for their contributions and to renew the cards every year".

His view on the expensive nature of the premiums was backed by views expressed by majority of the urban residents we interviewed. They explained that most rural households are trapped between extreme and relative poverty[1] and this prevents them from enrolling and remaining in the scheme. An interview participant from Jirapa informed us that:

"Most of villagers find it very difficult to get two meals in a day because of poverty. It is even worse during certain periods of the dry season. So raising funds to pay for health insurance is almost impossible for them".

Health providers who participated in this study expressed views that are consistent with the views of users on the cost of premiums. A medical doctor at the Jirapa Municipal Hospital and a public health nurse at the Jirapa Municipal Health Directorate were sympathetic to the poor in general but added that rural residents are the most affected by the high costs of premiums. They focused on the large sizes of households in these areas and argued that their subsistence farming would not generate enough income to pay for health insurance. The public health nurse explained that:

"When you compare the cost of premiums to user fee charges you would conclude that the premiums are far lower and affordable. However, when you analyse the costs of premiums for a rural household per annum, you would realise that the majority of them cannot enrol in the scheme". 
Another finding that emerged as a consequence of expensive premiums is adverse selection, a situation where those with high health risk profiles such as women and children are insured and those with a lower chance of getting sick abstain. Majority of the participants expressed that large household size coupled with the seasonality of incomes in this context make it difficult for them to raise enough money to pay the premiums of every member of the household. This has forced households to resort to adverse selection. A resident of Yaga, who heads a household is one of the interviewees who lamented about selecting out of the scheme as a result of the inability of his family to raise enough funds to purchase health insurance. In relation to the cost of premiums, he informed us in an interview:

"I just managed to raise enough money for my wife and two of my younger children. My three older sons and I have dropped out of the scheme because it is too expensive and we couldn't afford it."

This view was validated during interactions with officials and agents of the NHIS. In their estimation, about 90 percent of registrants are within the exempt group, which includes pregnant women, the elderly, aged 70 years and above, as well as indigents. And more than half of the remaining 10 percent are unable to renew their membership on time. The rest renew their membership only when they are sick and need treatment at a health facility. An official of the scheme shared with the researchers that:

"When you see somebody here (NHIS office) very early in the morning waiting to renew a card for themselves or for a family member, they are sick and need insurance cover to go to the hospital. And this happens all the time".

Interactions with the NHIS agents confirmed that poor households were adversely selecting in the scheme. They explained that in order to avoid catastrophic spending, men normally abstain or select out of the scheme to allow their wives and children to enrol on the grounds that they are more vulnerable to sickness. An agent explained that:

"The premium is not affordable at all. Looking at our condition here in Jirapa many people cannot afford it. Initially, it was Ghष7.20 per adult and children were not paying once their parents were registered. [2] Now it is not the case, the fee is gone up and children are required to pay processing fee. Imagine someone with ten children, it is impossible to register all of them. This is why you find that in some households, only children and women are registered while the men are not".

Contrary to the views above, all the three officials of the NHIS interviewed were of the view that the premiums are affordable to households and those who cannot afford (i.e. Indigents) are granted exemption. One of them had this to say about the costs of premiums:

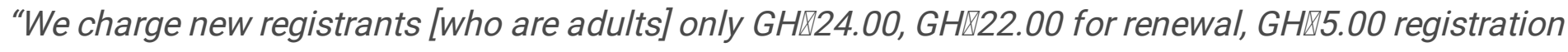
fee for children and GHख2.00 for their renewal. The premiums charged in this district are the lowest in the country. They are also low compared to what users pay out-of-pocket for treatment in the absence of a national health insurance cover." 
Surprisingly however, a few rural residents agreed with the view expressed by the officials. They expounded that prior to the introduction of the NHIS, they paid more money out-of-pocket for treatment in health facilities. A resident of Tuggo stated in relation to the cost of premiums that:

"The premiums are not really expensive as people say they are. We used to pay more during the cash-andcarry days. The only problem is that most of us have many children and for that reason we need to plan and save money towards NHIS payments."

The main finding from the analysis of the cost of NHIS premiums is a perception by majority of users, providers and NHIS agents that the NHIS premiums are expensive for the majority of people resident in the Municipality. This view, however, contradicts the position of NHIS officials who argued that the premiums were reasonably low.

\section{Rigidity of Payment of Contributions}

With the exception of the three officials of the scheme who participated in the study there was a consensus among users, providers, and agents that the timing of collection of contributions from people in the informal sector, particularly farming households was mostly inconvenient. Interview interactions with farming households revealed their preference for premiums to be collected between October and December when they are able to generate funds from the sale of their farm produce. This preference is influenced by the seasonal nature of their main livelihood activities.[3] Thus, the best time to collect contributions is when the residents are harvesting farm produce and may have surplus to sell to raise funds to pay premiums. A subsistence crop farmer in Tuggo decried that:

"It is not possible for us to keep some money from the sale of farm produce and pay for health insurance any time of the year. The best time is when we harvest our produce. If we knew when he (NHIS agent) would be coming, we would go to the village market, sell some grains and put the money aside. Unfortunately, he [NHIS agent] comes around unannounced, but also at a time when we are not prepared financially."

A previously enrolled rural interviewee from Kul-Ora suggested that in addition to scheduling the timing for collection of contributions, the NHIS should consider spreading the contributions over a reasonable period within a year instead of the current one-off annual payment system. He observed that:

"The current payment arrangement is rigid and unfavourable to most of us who have large families. We cannot afford to pay the premiums for eight people at once. The best way is for the scheme to be flexible to spread payment over the whole year for households that genuinely cannot afford the one-off payment due to large numbers."

Community agents, whose tasks include registering new members and renewing members' subscriptions, conceded that enrolment and renewal figures are very low between January and September. This is the pre-cropping and cropping seasons when farming households do not have enough produce in stock to sell and raise funds for health insurance contributions. An opinion that reflects the aforementioned 
difficulty was expressed by an NHIS agent for the Douri Zone. When asked about the appropriateness of the timing of collection of contributions, he explained:

"Most households are struggling to raise funds to pay for health insurance. Since I started this work many years ago (since 2010) the period I get clients to subscribe is October and December. Aside from this period the group of people who subscribe anytime of the year are the exempt group (pregnant women, indigents and aged)."

However, officials of the NHIA disagreed with these view when asked about the appropriateness of the timing for collection of premiums. They insisted that there was nothing wrong with the timing of collection of premiums and that subscribers ought to learn to put money aside for the payment of NHIS premiums. A senior official at the Upper West Regional secretariat asserted regarding the timing of collection of premiums that:

"There is nothing wrong with the timing. In fact, most of these men who are complaining about poor timing spend money on other things every day. They drink alcohol and eat meat, buy cigarettes, spend so much moving from one funeral venue to another, and yet they cannot afford to pay GHS 22.00 a year for health insurance? Those who genuinely cannot pay (indigents) are exempted from paying the premiums."

Clearly, the analysis throws up differences in perceptions of participants on the timing of collection of premiums from people in the informal sector who were mostly engaged in seasonal livelihood activities. An important point to highlight in connection with rigid payment of premiums however is that whereas the NHIS seems to analyse the costs of premiums on individual basis, the reality is that when it comes to enrolling in the NHIS the decision is normally a household affair. An important determining factor of enrolment has been the size of income of the household, and where this was limited priority was accorded those members with high risks of falling sick (mostly women and children). This explains why adverse selection is a common strategy employed by poor households to cope with the burden of health care costs and to avoid catastrophic spending.

\section{Discussion}

This study explored the question of vertical equity in the NHIS using a qualitative research approach, and uncovered evidence of vertical inequity in distribution of cost and lack of flexibility and adaptability of timing premium collections to the needs of the poor and the policy implications for improving equity in health care through the NHIS. Rural residents do not have access to NHIS services to the extent as their urban counterparts mainly because the membership fees[1] are perceived to be expensive relative to their incomes. Additionally, the mode of paying membership fees is deemed to be unfavourable to a significant number of households who have seasonal subsistence farming as the main source of livelihood. 
The discourse on equity of NHIS premiums has been ongoing, with several studies exploring the subject from different perspectives. Using an in-depth approach this study explored whether the NHIS has delivered on vertical equity as variations in livelihood activities of urban and rural households require the implementation of equity measures to ensure that rural residents are treated differently in a way that is seen to be commensurate with their relative disadvantage. We found in this study that an important element that has been ignored in the determination of membership fees is the average size of rural households and how this influences ability to pay. In the Jirapa Municipality (which is largely rural), the average household size is 6.3 persons (51). Like other schemes in the country, the Jirapa Municipal Health Insurance Scheme charges informal sector contributors aged between 18 and 69 years GHS3.00 for the premium and GHS7.00 as processing fee.[2] This suggests that the total costs of membership fees per household could be as high as GHS189 per annum. Although a few rural residents surprisingly find these charges to be affordable, a considerable number of seasonal subsistence crop farming households are unable to pay due to fiscal constraints. Evidence of extreme levels of poverty in rural areas is drawn from the Ghana Living Standards Survey Round 7 (GLSS7) report which reveals that the Upper West Region has the highest incidence of poverty (70.9\%) while the Greater Accra Region is the least poor (2.5\%). The Region's poverty figure (70.9\%) also far exceeds the national average of 23.4 percent (55). The report further observed that while poverty is predominantly a rural phenomenon, households with heads who are farmers are not only the poorest but they contribute the most to the country's poverty. This disproportionate share and widespread nature of poverty in rural areas makes the NHIS practice of charging flat rate premiums to people outside of the formal sector inequitable. More so, flat rate contributions contradict Act 852, section 28 of the legal instrument establishing the NHIA, which states that contributions by populations in the informal sector be graduated according to income levels? (34). The rationale is that payment of contributions should not result in catastrophic household expenditure. Their inability to enrol in the scheme deprives them of access to health care, even though, according to Hjortsberg and Mwikisa (58), they are more susceptible to illnesses than their urban counterparts. Based on the results of this study, backed by the GLSS7 finding that poverty is disproportionally high in rural areas and among farming households, we argue that rural residents could be suffering a higher burden of the costs of enrolling in the NHIS than their urban counterparts. The flat rate contributions slapped on those in the informal sector of the economy and the rigidity in the timing of collection of contributions constitute vertical inequity and a failure to implement important design elements of the scheme. The scheme's vertical equity objectives are a deliberate undertaking aimed at extending financial access to health care at a cost that is commensurate with users' income and a recognition of the seasonality of the incomes of poor households. (33) observes that the consequences of paying flat rate contributions on inflexible terms can be catastrophic for poor households. The NHIS has so far not been able to graduate contributions according to income for populations in informal sector, although it is by law mandated to do so (34). Some scholars have attributed the Scheme's inaction to the absence of reliable income records for a large proportion of the population that fall outside the formal sector of the economy $(6,37)$. In the Jirapa Municipality where the majority of the population is employed in subsistence agriculture and without reliable records of their income to qualify to contribute based on income, adverse selection and moral hazards were a common means of avoiding catastrophic

Page $14 / 22$ 
expenditure. The residents would often enrol or renew the membership of household members who are most likely to fall sick[3] or renew their membership only when they were sick. To achieve equity in enrolment in the NHIS would require a review of the current flat rate contributions levied on subscribers outside the formal sector. This will make the premiums equitable to enable individuals and households enrol without the risk of catastrophic spending. To this end policy makers and implementers need to sustain their commitment to the ongoing effort by the Ministry of Gender, Children and Social Protection to develop a national household register that will provide reliable information from which membership fees can be determined on basis of household income.

The burden of inequitable membership contributions for populations in the informal sector of the economy is compounded by rigid payment arrangements. This emerged not just as an enrolment barrier but as a challenge faced mostly by rural residents than their urban counterparts. Earlier studies which examined the timing of collection of contributions for socio economic groups came to the conclusion that payment of contribution needs to be scheduled to match with periods when the households have surplus income (40-44). We found in this study that variation in livelihood activities among urban and rural populations creates differences in preferences of the timing of collection of NHIS contributions. The differences in sources of income between populations in these localities call for favourable timing for the payment of contributions in order to minimize lapses, and maximize enrolment and renewals. Farming households prefer to pay their contributions between October and December when they have raised funds from the sale of farm produce. This is consistent with Wipf, Liber (43) earlier observation that payment of insurance contributions ought to be timed to coincide with the income streams of users. Contrary to this, the Jirapa Municipal Scheme operates an open registration system for all residents without observing the October-December timeframe for which the majority of the population prefer to pay the membership contributions. While observing the preferred payment schedule for farming household is important given the size of the population of the Municipality, for other informal sector workers, flexible payment options such as monthly, quarterly, semi-annual and annual payment options may be preferred by different segments of the of the population.

Eliminating vertical inequity in the NHIS enrolment would require a two stage process, starting with a redesign of scheme's fee payment structure to reflect the categorization of households articulated in the National Household Register (i.e. extremely poor, poor and non-poor). Once the incomes of households are known, the second step will be a strict implementation of Act 852, section 28 of the LI establishing the $\mathrm{NHIA}$, which requires that premiums for populations in the informal sector be graduated according to income. This is important because the NHIS is mandated to deliver on equity yet the journey towards this objective has mainly been impeded by implementation challenges - absence of reliable households' income records. Fortunately, the solution does not seem far off because the ongoing process to develop a national household register would make possible the implementation of positive discrimination measures. These would include granting exemption from payment of contributions to all those registered as extremely poor (indigents), granting free access to primary health care to those registered as poor, graduating contributions according to the incomes of those in the informal sector and adapting fee payment arrangements to suit those known to be relying on seasonal sources of income. These 
measures will promote vertical equity in the delivery of services under the NHIS and make health care financially accessible to the poor, particularly those residing in rural areas.

\section{Conclusion And Policy Implications For Planning}

This paper concludes based on its findings that the NHIS has not delivered on vertical equity. There is evidence of inequity arising from expensive membership fees and the mode of payment that appears to be unfavourable to a considerable proportion of rural households who rely mainly on seasonal subsistence agriculture for income. The NHIS is charging flat rate contributions to populations outside the formal sector as a result of the absence of reliable income records which would ensure that payments of fees are commensurate with incomes. The consequences of this is low enrolment, adverse selection, moral hazards and dropouts, mostly among poor rural populations. The absence of insurance cover means that users will be required to pay out-of-pocket fees at the point of service use, which might be catastrophic or impoverishing for poor households. Users who are unable to pay out-of-pocket fees may delay medical treatment, self-medicate or resort to quack medicine practitioners, all of which are unsafe. To this end, we recommend the adoption of positive discrimination measures in order to achieve the scheme's objective of ensuring that every Ghanaian resident has financial access to basic health care.

\section{Abbreviations}

GLSS: Ghana Living Standards Survey; GNHR: Ghana National Household Register; LEAP: Livelihood Empowerment Against Poverty; LMIC: Low and Middle Income Countries; NHIA: National Health Insurance Authority; NHIS: National Health Insurance Scheme; SDG: Sustainable Development Goals; UHC: Universal Health Coverage; UN: United Nations; WHO: World Health Organization.

\section{Declarations}

Ethics approval and consent to participate

Ethics approval was not required for this research because it involved simple uncontentious questions and the content is uncontroversial. Appropriate permissions were obtained from interviewees (i.e. informed consent) and the information obtained remains confidential, and quotations have been anonymised.

Consent for publication

Not applicable.

Availability of data and materials

All data generated or analysed during this study are included in this published article.

Competing interests 
The authors declare that they have no competing interests

Funding

No funding was received for this work.

Authors' contributions

MKD conceptualised the study, reviewed the literature, developed the methodology, carried out data collection and analysis, interpreted the findings and wrote the original draft and final manuscript. CAA contributed to the analysis of data, interpretation of findings, reviewed and edited the original draft. EKD contributed to the interpretation of the findings and reviewed the content and structure of the manuscript. All authors read and approved the final manuscript.

\section{References}

1. Mooney G. Vertical equity in health care resource allocation. Health Care Analysis. 2000;8(3):203-15.

2. NHIA. NHIS Active membership report for December 2018 (final as at April 1 2019. Accra, Ghana: National Health Insurance Authority; 2019.

3. Nsiah-Boateng E, Nonvignon J, Aryeetey GC, Salari P, Tediosi F, Akweongo P, et al. Sociodemographic determinants of health insurance enrolment and dropout in urban district of Ghana: a cross-sectional study. Health economics review. 2019;9(1):23.

4. Mills A, Ally M, Goudge J, Gyapong J, Mtei G. Progress towards universal coverage: the health systems of Ghana, South Africa and Tanzania. Health policy and planning. 2012;27(suppl_1):i4-i12.

5. WHO. Tracking universal health coverage: 2017 global monitoring report. Geneva: World Health Organization; 2017.

6. Borghi J. Achieving universal coverage In: Guiness L, Wiseman V, editors. Introduction to Health Economics. London: Open University Press; 2011.

7. McIntyre D, Mills A. Research to support universal coverage reforms in Africa: the SHIELD project. Oxford University Press; 2012.

8. WHO. Health systems financing: The path to universal coverage. World health report 2010. Geneva: World Health Organization; 2010.

9. Ranabhat CL, Atkinson J, Park M-B, Kim C-B, Jakovljevic M. The influence of universal health coverage on life expectancy at birth (LEAB) and healthy life expectancy (HALE): a multi-country cross-sectional study. Frontiers in pharmacology. 2018;9:960.

10. Owusu AY. The Linkage between Health and Development. . In: ASANTE FA, OWUSU AY, AHIADEKE C, editors. Placing Health at the Centre of Development. Accra, Ghana: Institute for Statistical and Economic Research (ISSER), University of Ghana; 2014.

11. Tangcharoensathien V, Mills A, Palu T. Accelerating health equity: the key role of universal health coverage in the Sustainable Development Goals. BMC medicine. 2015;13(1):101. 
12. Ramachandra S, Hsiao W. Ghana: initiating social health insurance. Social health insurance for developing nations. 2007;434:61.

13. Chankova S, Atim C, Hatt L. Ghana's Health Insurance Scheme. . In: Escobar ML, Griffin CC, Shaw RP, editors. The Impact of Health Insurance in Low-and-Middle-Income Countries Washington DC: Brookings Institute Press; 2010.

14. Agyepong IA, Adjei S. Public social policy development and implementation: a case study of the Ghana National Health Insurance scheme. Health policy and planning. 2008;23(2):150-60.

15. Agyepong IA, Orem JN, Hercot D. When the 'non-workable ideological best'becomes the enemy of the 'imperfect but workable good'. Tropical Medicine \& International Health. 2011;16(1):105-9.

16. Mensah J, Oppong JR, Schmidt CM. Ghana's National Health Insurance Scheme in the context of the health MDGs: An empirical evaluation using propensity score matching. Health economics. 2010;19(S1):95-106.

17. Waddington CJ, Enyimayew K. A price to pay: The impact of user charges in Ashanti-Akim district, Ghana. The International Journal of Health Planning and Management. 1989;4(1):17-47.

18. Oppong JR. Structural Adjustment and the Health Care System. In: AGYEMANG KK, editor. IMF and World Bank Sponsored Structural Adjustment Programs in Africa: Ghana's Experience, 1983-1999. Aldershot: Ashgate; 2001.

19. Boom V, Nuamah N, Overbosch G, editors. Curative health care utilization in Ghana: a multinomial analysis of equitable access opportunities 2004.

20. Jan S, Wiseman V. Equity In: Guinness L, Wiseman V, editors. Introduction to health economics. London Open University Press; 2011.

21. Donaldson C, Gerard K. Economics of health care financing: Springer; 1993.

22. Whitehead M. The concepts and principles of equity and health. Health promotion international. 1991;6(3):217-28.

23. Whitehead M, Dahlgren G, Evans T. Equity and health sector reforms: can low-income countries escape the medical poverty trap? The Lancet. 2001;358(9284):833-6.

24. Kanmiki EW, Bawah AA, Phillips JF, Awoonor-Williams JK, Kachur SP, Asuming PO, et al. Out-ofpocket payment for primary healthcare in the era of national health insurance: Evidence from northern Ghana. PloS one. 2019;14(8).

25. Akazili J, Welaga P, Bawah A, Achana FS, Oduro A, Awoonor-Williams JK, et al. Is Ghana's pro-poor health insurance scheme really for the poor? Evidence from Northern Ghana. BMC health services research. 2014;14(1):637.

26. Atinga RA, Abiiro GA, Kuganab-Lem RB. Factors influencing the decision to drop out of health insurance enrolment among urban slum dwellers in Ghana. Tropical Medicine \& International Health. 2015;20(3):312-21.

27. Jehu-Appiah C, Aryeetey G, Spaan E, De Hoop T, Agyepong I, Baltussen R. Equity aspects of the National Health Insurance Scheme in Ghana: Who is enrolling, who is not and why? Social science \& 
medicine. 2011;72(2):157-65.

28. Brugiavini A, Pace N. Extending health insurance in Ghana: effects of the National Health Insurance Scheme on maternity care. Health economics review. 2016;6(1):7.

29. Kotoh AM, Aryeetey GC, Van der Geest S. Factors that influence enrolment and retention in Ghana'National Health Insurance Scheme. International journal of health policy and management. 2018;7(5):443.

30. Macha J, Harris B, Garshong B, Ataguba JE, Akazili J, Kuwawenaruwa A, et al. Factors influencing the burden of health care financing and the distribution of health care benefits in Ghana, Tanzania and South Africa. Health policy and planning. 2012;27(suppl_1):i46-i54.

31. Mills A, Ataguba JE, Akazili J, Borghi J, Garshong B, Makawia S, et al. Equity in financing and use of health care in Ghana, South Africa, and Tanzania: implications for paths to universal coverage. The Lancet. 2012;380(9837):126-33.

32. Wiseman V, Jan S. Resource allocation within Australian indigenous communities: a program for implementing vertical equity. Health care analysis. 2000 8:217-33.

33. McClelland A. In fair health?: equity and the health system: National Health Strategy; 1991.

34. NHIA. National Health Insurance Act, 2012 (Act 852). Accra: GPCL/Assembly Press.: National Health Insurance Authority; 2012.

35. Witter S, Garshong B. Something old or something new? Social health insurance in Ghana. BMC international health and human rights. $2009(9,20$.$) .$

36. Apoya P, Marriott A. Achieving a shared goal: free universal health care in Ghana: Oxfam International; 2011.

37. Averill C, Marriott A. Universal health coverage: why health insurance schemes are leaving the poor behind: Oxfam International; 2013.

38. Schieber G, Cashin C, Saleh K, Lavado R. Health financing in Ghana: The World Bank; 2012.

39. GNHR. Ghana National Household Register Accra Ghana.: Ministry of Gender, Children and Social Protection; 2020 [Available from: http://www.gnhr.mogcsp.gov.gh/ Access Date: 06/06/2020.

40. Carrin G. Community based Health Insurance Schemes in Developing Countries: facts, problems and perspectives. 2003. World Health Organization: Geneva. 2003.

41. Cohen M, Sebstad J. Protecting the poor: A microinsurance compendium In: Churchill C, editor. The demand for microinsurance. Geneva.: International Labor Organisation; 2006.

42. De Allegri M, Sanon M, Sauerborn R. "To enrol or not to enrol?": a qualitative investigation of demand for health insurance in rural West Africa. Social science \& medicine. 2006;62(6):1520-7.

43. Wipf J, Liber D, Churchill C. Product design and insurance risk management. In: CHURCHILL C, editor. Protecting the poor: A microinsurance compendium. Geneva: International Labour Organization; 2006.

44. Owusu A, Afutu-Kotey R, Kala M. Access to micro health insurance in Ghana: Literature review and proposed analytical framework. Handbook of Micro Health Insurance in Africa Muenster: Lit Verlag. 
2012.

45. McIntyre D, Muirhead D, Gilson L. Geographic patterns of deprivation in South Africa: informing health equity analyses and public resource allocation strategies. Health policy and planning. 2002;17(suppl_1):30-9.

46. Mclntyre $D$, Thiede M, Birch S. Access as a policy-relevant concept in low-and middle-income countries. Health Economics, Policy and Law. 2009;4(2):179-93.

47. Penchansky R, Thomas JW. The concept of access: definition and relationship to consumer satisfaction. Medical care. 1981:127-40.

48. WHO. Tracking universal health coverage: first global monitoring report, . Geneva: World Health Organization; 2015.

49. Aday LA, Andersen R. A framework for the study of access to medical care. Health services research. 1974;9(3):208.

50. ILO. Social health protection: An ILO strategy towards universal access to health care. 2008.

51. GSS. 2010 Population and Housing Census: District Analytical Report, Jirapa Municipal. Accra: Ghana Statistical Service.; 2014.

52. GHS. Annual Report: Jirapa Municipal Health Directorate. Jirapa: Ghana Health Service; 2020.

53. Cooke E, Hague S, McKay A. The Ghana poverty and inequality report: Using the 6th Ghana living standards survey. University of Sussex. 2016.

54. GSS. Ghana poverty mapping report. Accra: Ghana Statistical Service.; 2015.

55. GSS. Ghana Living Standards Survey Round 7 (GLSS 7): Poverty Trends in Ghana 2005-2017. Accra: Ghana Statistical Service.; 2018.

56. NHIS. Annaul report: National Health Insurance Scheme, Jirapa Municipal. Jirapa, Ghana: National Health Insurance Authority; 2020.

57. Brockington D, Coast E, Mdee A, Howland O, Randall S. Assets and domestic units: methodological challenges for longitudinal studies of poverty dynamics. The Journal of Peasant Studies. 2019:1-21.

58. Hjortsberg C, Mwikisa C. Cost of access to health services in Zambia. Health policy and planning. 2002;17(1):71-7.

\section{Figures}




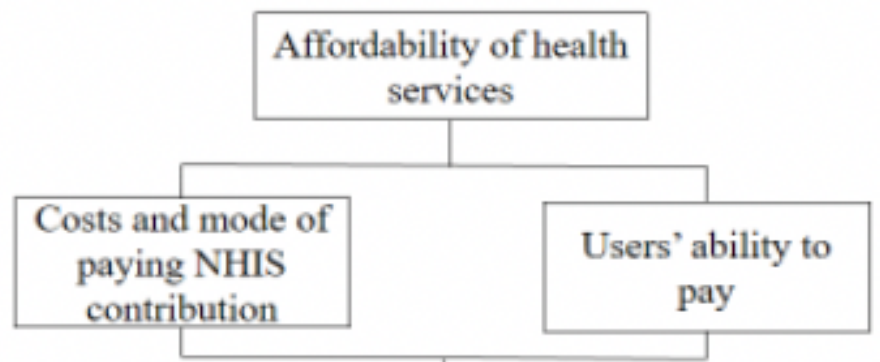

Increased enrolment in the NHIS and uptake of
health care

Vertical equity in the distribution of the costs and benefits of the NHIS

\section{Figure 1}

Conceptual framework for assessing vertical equity (Author's construct).

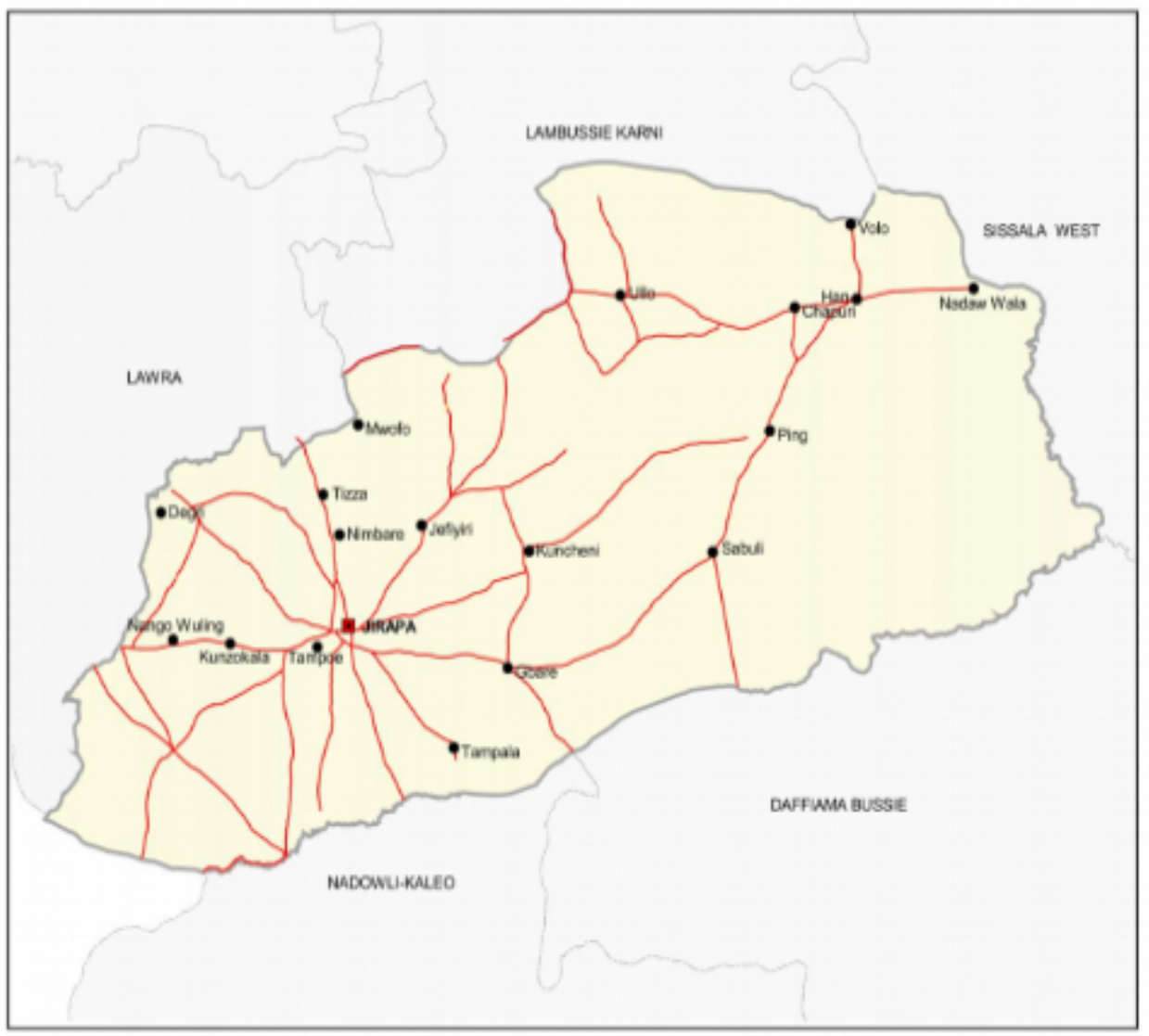

DISTRICT MAP OF JIRAPA

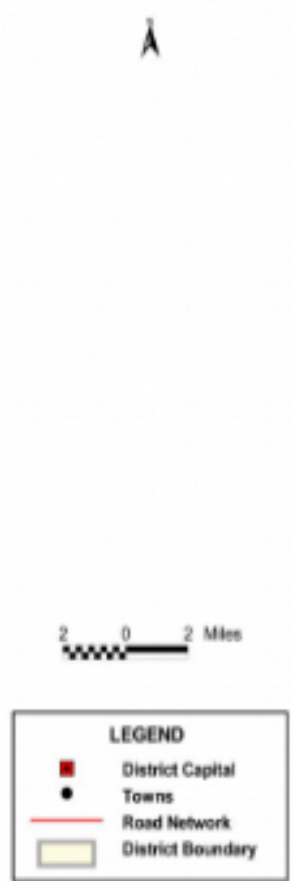

Figure 2

A Context map of Jirapa Municipality 


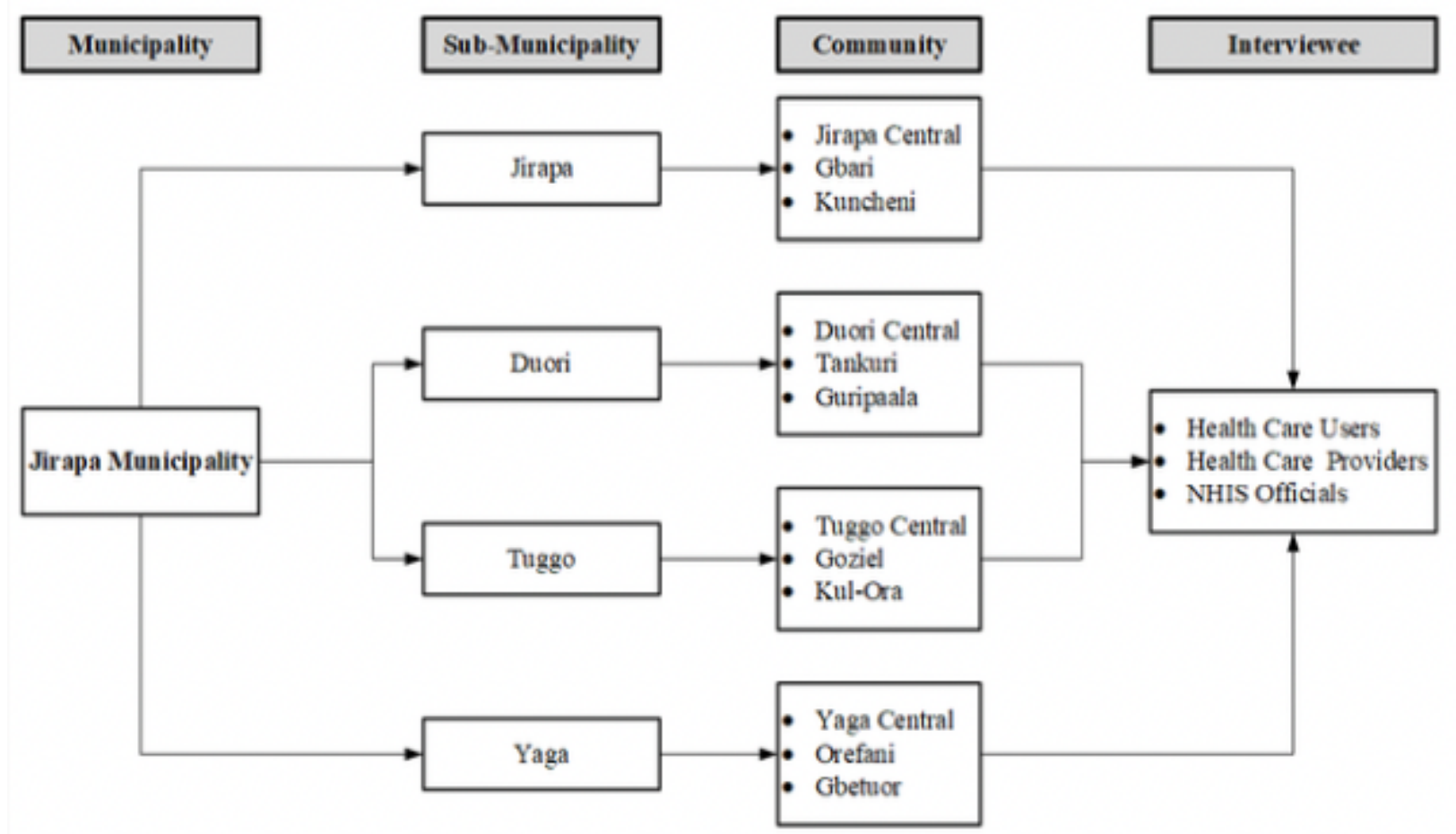

\section{Figure 3}

Multi-stage sampling strategy employed for the study. 